\title{
How to disseminate the mass unit for the new kilogram?
}

\author{
Zaccaria Silvestri $^{1, a}$, Saïd Bouhtiyya ${ }^{1}$, Patrick Pinot $^{1}$ and Stuart Davidson ${ }^{2}$ \\ ${ }^{1}$ Laboratoire commun de métrologie LNE-Cnam, 61 rue du Landy, 93210 La Plaine Saint-Denis, France \\ ${ }^{2}$ National Physical Laboratory, Hampton Road, Teddington, Middlesex, TW11 OLW, UK
}

\begin{abstract}
Résumé. En 2018, la Conférence Générale des Poids et Mesures (CGPM) actera certainement la nouvelle définition de l'unité de masse en se basant, non plus sur un artéfact matériel mais sur une constante physique fondamentale. C'est pourquoi, il est indispensable de repenser dès aujourd'hui l'échelle de masse actuelle en développant de nouveaux moyens «pratiques» de dissémination de ce «nouveau kilogramme». Par conséquent, cet article décrit quelques études réalisées dans le cadre du projet européen NewKILO pour la réalisation de nouveaux étalons de masse utilisables sous vide et/ou gaz neutre mais aussi le développement de nouvelles méthodes de nettoyage (UV/Ozone, plasma, thermo désorption,...) et de transfert (vide-air ou vide-azote).
\end{abstract}

\section{Introduction}

The unit of mass, the kilogram, is the only remaining base units of the SI still defined by a material artefact rather than by relation to an invariant of nature. Progress is being made towards a redefinition in terms of the Planck constant, realised via the watt balance [1]-[5] and Avogadro (or X-ray crystal density) experiments [6], [7]. The accuracy of these experiments is nearing that required by the mass community $\left(2\right.$ parts in $\left.10^{8}\right)$ and the CIPM has targeted the 2018 meeting of the CGPM [8] for the ratification of the redefinition and in order for this to be feasible, a practical means of linking the new definition to the current mass scale and to the end users must be in place.

The European SIB05 NewKILO project "Developing a practical means of disseminating the new kilogram"[9], started in June 2012 and ended in June 2015, aims to develop the procedures necessary to provide this link and to ensure the continuity of the worldwide mass scale. Without this work the uncertainty with which the Planck constant can be fixed will be compromised and furthermore the practical implementation of a redefined kilogram will not be possible.

This project is addressing requirements for the implementation of the redefinition of the kilogram by developing artefacts and protocols which will allow traceability to a vacuum realisation while minimising uncertainty both in the fixing of the Planck constant for redefinition and in the subsequent dissemination of the unit of mass.
The project is composed of five technical work packages (WP):

- Development of next generation mass standards with new materials that have optimised stability for transfer to vacuum and storage in vacuum and inert gas (WP1);

- Investigation of vacuum/air transfer phenomena and characterisation of the behaviour of various materials on transfer between vacuum, air and inert gas using complementary surface analysis techniques (WP2 and WP3);

- Production of apparatus for the storage and transfer of mass standards under vacuum or inert gas, and evaluation of cleaning methods for mass standards (WP4);

- Identification and evaluation of the uncertainty components inherent in the traceability to the new definition and in their propagation through the dissemination chain (WP5).

The different founded and unfounded partners of this project are: NPL (coordination, UK), BIPM, CMI (Czech Republic), CNAM (France), DFM (Denmark), EJPD (Switzerland), LNE (France), MHHEST (Slovenia), MIKES (Finland), PTB (Germany), SMU (Slovakia), TUBITAK UME (Turkey), INRIM (Italy), NRC (Canada). Additional collaborators include Häfner, Mettler-Toledo, Sartorius, Troemner, TU-Ilmenau, KRISS (Korea), IPQ (Portugal) and IMBiH (Bosnia and Herzegovina).

The paper will outline the main objectives and motivations of the project and discuss specifically some works carried out in few work packages (WP1, WP3 and WP4). This will include a review of new materials,

\footnotetext{
${ }^{a}$ Corresponding author: zaccaria.silvestri@enam.fr
} 
investigations of the effect of cleaning methods and the effect of mass stability in terms of contamination using different venting methods.

\section{Next generation of material for primary mass standards.}

The International Prototype Kilogram (IPK), which currently defines the mass scale, is a cylinder made in 1887 from a platinum and iridium alloy.

The choice of this alloy at this time was very good for the long term mass stability. The main characteristics of Pt-Ir are:

- Hardness (about $180 \mathrm{HV}$ ) that preserve the surface from wear and straches ;

- High density $\left(21500 \mathrm{~kg} / \mathrm{m}^{3}\right)$ that indicates a small surface area (about $71 \mathrm{~cm}^{2}$ ) ;

- Low physico-chemical reactivity in air.

However, to provide traceability to watt balance and Avogadro experiments and to maintain the mass scale, some properties for this new material has been selected:

- Low magnetic permeability $\left(<2 \times 10^{-4}\right)$ to allow use on the watt balance experiment where the magnetic field in the apparatus is very strong (about $1 \mathrm{~T}$ for French watt balance). Pt-Ir alloy presents a magnetic susceptibility of $2.5 \times 10^{-4}$ that require a significant correction;

- Hardness (HV > 200) to facilitate machining, mirror polishing and to reduce wear when manipulating the mass;

- High chemical resistance with regard to corrosion and oxidation for instance;

- Good homogeneity without porosity, cavity and occluded gases in order to guarantee long-term stability;

- Sufficient electrical conductivity to avoid accumulating electrostatic charges and good thermal conductivity to minimize temperature effects when weighing in air.

Finally, the next generation mass standards will be optimised for transfer between air and vacuum and for stability when stored in vacuum or inert gas.

With these properties, several materials have been selected and compared: pure iridium, gold and nickel alloys (Udimet 720), gold and rhodium plated copper and silicon. Table 1 presents the main advantages and disadvantages properties of each selected material [10].

Table 1- Comparison of selected materials for use as primary mass standards for the redefinition of the kilogram [10].

\begin{tabular}{|l|l|l|}
\hline Material & Advantages & Disadvantages \\
\hline $\begin{array}{l}\text { Platinum- } \\
\text { iridium }\end{array}$ & $\begin{array}{l}\text { Well characterised } \\
\text { material [11] } \\
\text { Easy to machine }\end{array}$ & $\begin{array}{l}\text { Expensive } \\
\text { Relatively high } \\
\text { magnetic } \\
\text { permeability [12] }\end{array}$ \\
\hline Stainless steel & $\begin{array}{l}\text { Well characterised } \\
\text { material } \\
\text { Used for the majority } \\
\text { of current weights }\end{array}$ & $\begin{array}{l}\text { High magnetic } \\
\text { permeability } \\
\text { Complex alloys - } \\
\text { Surfaces difficult } \\
\text { to analyse }\end{array}$ \\
\hline
\end{tabular}

\begin{tabular}{|c|c|c|}
\hline Silicon & $\begin{array}{l}\text { Excellent surface } \\
\text { finish achievable } \\
\text { Natural silicon } \\
\text { Readily available } \\
\text { Very low magnetic } \\
\text { permeability }\end{array}$ & $\begin{array}{l}\text { Low density so } \\
\text { must be weighed } \\
\text { in vacuum } \\
\text { Potential static } \\
\text { issues }\end{array}$ \\
\hline Gold alloy & $\begin{array}{l}\text { Good magnetic } \\
\text { properties } \\
\text { Easy to machine } \\
\text { Dense }\end{array}$ & $\begin{array}{l}\text { Low relative } \\
\text { hardness } \\
\text { Samples analysed } \\
\text { showed } \\
\text { anomalous } \\
\text { sorption } \\
\text { characteristics }\end{array}$ \\
\hline Iridium & $\begin{array}{l}\text { Hard } \\
\text { Good magnetic } \\
\text { properties } \\
\text { Dense }\end{array}$ & $\begin{array}{l}\text { Difficult to } \\
\text { machine } \\
\text { Expensive }\end{array}$ \\
\hline $\begin{array}{l}\text { Nickel super } \\
\text { alloy } \\
\text { (Udimet 720) } \\
\text { [13] }\end{array}$ & $\begin{array}{l}\text { Similar density to } \\
\text { stainless steel } \\
\text { Hard } \\
\text { Good magnetic } \\
\text { properties }\end{array}$ & $\begin{array}{l}\text { Relatively } \\
\text { expensive and } \\
\text { difficult to obtain }\end{array}$ \\
\hline Tungsten & $\begin{array}{l}\text { Excellent magnetic } \\
\text { properties } \\
\text { Density similar to } \\
\text { that of } \mathrm{Pt}-\mathrm{Ir}\end{array}$ & $\begin{array}{l}\text { Difficult to } \\
\text { manufacture } \\
\text { artefacts } \\
\text { High quality } \\
\text { crystals of suitable } \\
\text { size expensive and } \\
\text { difficult to obtain }\end{array}$ \\
\hline $\begin{array}{l}\text { (Gold and } \\
\text { rhodium) plated } \\
\text { copper }\end{array}$ & $\begin{array}{l}\text { Excellent magnetic } \\
\text { properties } \\
\text { Easy to manufacture } \\
\text { Similar density to } \\
\text { stainless steel }\end{array}$ & $\begin{array}{l}\text { Surface relatively } \\
\text { soft } \\
\text { Quality of } \\
\text { artefacts relies on } \\
\text { good coating } \\
\text { process }\end{array}$ \\
\hline
\end{tabular}

Among the work of studies on these materials such as measurements of hardness or magnetic susceptibility, the evaluation of the roughness of the surface after polishing process has been evaluated at Cnam using an angleresolved scatterometer (ARS) [14]. With this device, angular distribution of the scattered light is performed in order determine the rms height from the power spectral density (PSD) [15]. This PSD is a signature of the surface for a given spatial frequencies domain (see Figure 1). 


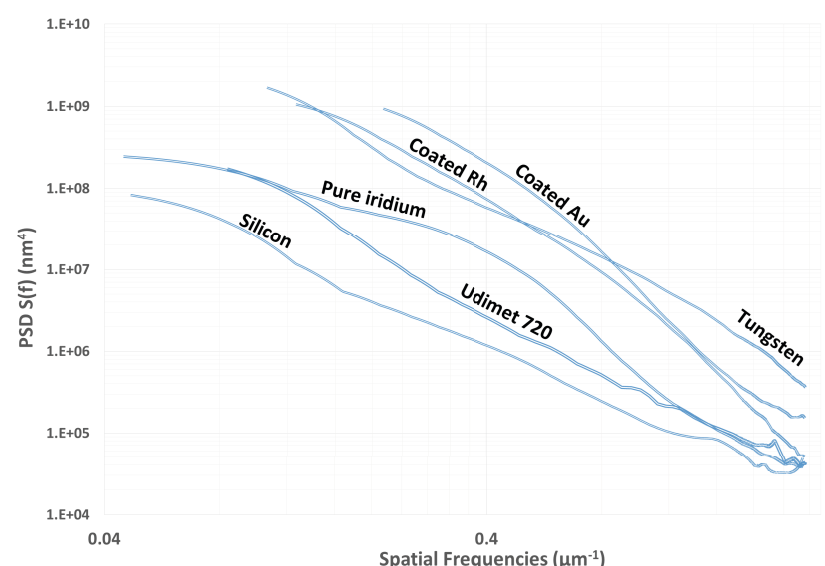

Figure 1- Mean PSD curves for each material in the spatial frequencies domain $[0.1-2.7] \mu \mathrm{m}^{-1}$.

From the comparison of the PSDs, we can note that each material has a characteristic PSD of share its allure and its amplitude.

The value of the rms height (Table 2) in the range [0.1 2.7] $\mu \mathrm{m}^{-1}$, gave a higher roughness for gold plated copper, tungsten rhodium plated copper than iridium, Udimet 720 and silicon.

Table 2 - Values of the rms height of the surface in the spatial frequencies domain [0.1-2.7] $\mu \mathrm{m}^{-1}$.

\begin{tabular}{|l|c|}
\hline \multicolumn{1}{|c|}{ Material } & Rms height (nm) \\
\hline Gold plated copper & $16.4 \pm 0.7$ \\
\hline Tungsten & $12.5 \pm 0.5$ \\
\hline Rhodium plated copper & $9.5 \pm 0.3$ \\
\hline Iridium & $4.0 \pm 0.3$ \\
\hline Udimet 720 & $2.4 \pm 0.3$ \\
\hline Silicon & $1.6 \pm 0.1$ \\
\hline
\end{tabular}

They is no direct relation link between roughness and mass stability but the roughness has an impact on the sorption. Others investigations of characterization of the surface have been carried out during the project [10].

\section{Cleaning of next generation of mass standards.}

The nettoyage-lavage method [16], [17] is the usual and historical method to clean the surface of the primary mass standard but its presents the disadvantage of a weak reproducibility due to manual processes. To improve the reproducibility with controllable parameters, new cleaning methods have been developed and compared in mass laboratories such as UV/Ozone [18], [19], lowpressure plasma [20]-[22] and thermal desorption [23].

For example, Cnam has compared low pressure airplasma and the nettoyage-lavage method, first on Pt-Ir alloy. Figure 2 shows the results of comparisons taken before and after one of each cleaning. It appears after each cleaning operation an increase in mass, and it appears to change logarithmically with time, tending to a relatively stable value after 8 days.

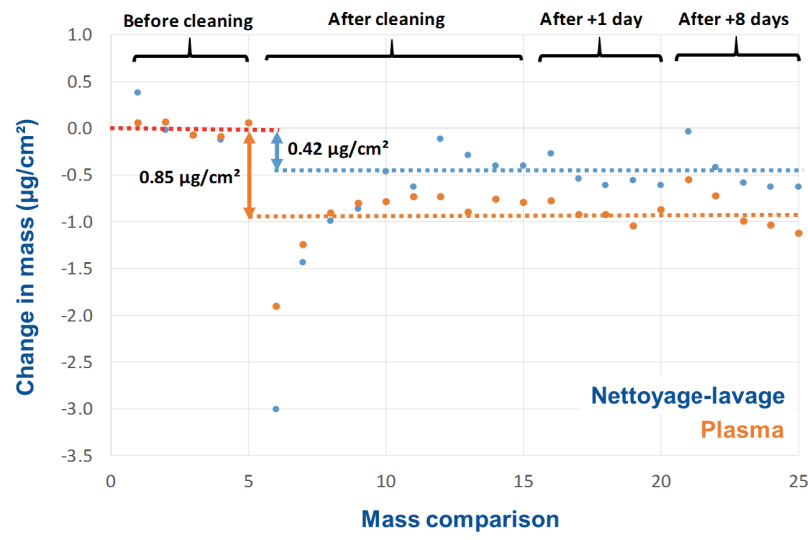

Figure 2 - Change in mass for a PtIr artefact after nettoyagelavage method and air-plasma cleaning.

The gravimetric measurements show that air-plasma cleaning works better than the nettoyage-lavage method due to various phenomena such as surface sterilization, combined effect of sputtering and desorption by chemical reactions of surface. The mass change is about 0.42 $\mu \mathrm{g} / \mathrm{cm}^{2}$ for nettoyage-lavage and $0.85 \mu \mathrm{g} / \mathrm{cm}^{2}$ for low pressure air-plasma.

An analysis contamination shows that the air-plasma cleaning is efficient for masses more than $50 \mathrm{u}$ (see mass spectra on Figure 3) compared to pre-cleaned samples. 


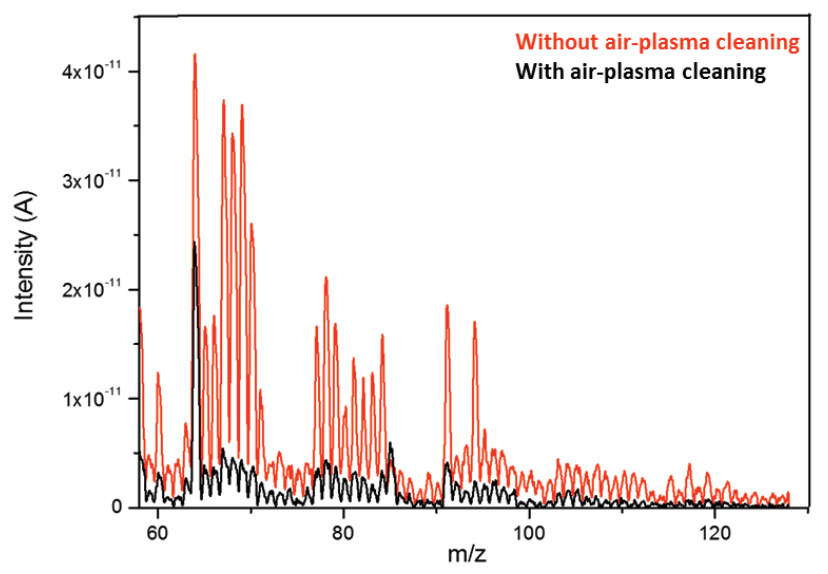

Figure 3 - TDS Mass spectra comparison between Pt-Ir artefact cleaned or not with air-plasma. The temperature of analysis is about $260{ }^{\circ} \mathrm{C}$.

\section{Transfer of next generation of mass standards.}

Due to the present definition of the kilogram, mass comparisons are carried out in air but with the new definition and the nature of the watt balance and Avogadro experiments, it will be necessary to transfer or store (short or long term) mass standards in vacuum and/or inert gas.

Three transfer cycles have been tested in order to optimize mass stability and possible recontamination:

- Cycling vacuum-air-vacuum;

- $\quad$ Cycling vacuum- $\mathrm{N}_{2}$-vacuum;

- Cycling vacuum- $\mathrm{N}_{2}$-air-vacuum.

METAS [24] has compared the different cycling XPS whereas Cnam has used a Thermal Desorption mass Spectrometry (TDS, Figure 4). Surface analysis on TDS can only be performed under vacuum (about $10^{-6} \mathrm{~Pa}$ ) where the contamination is removed with a maximum heating temperature of $600{ }^{\circ} \mathrm{C}$ during 2 hours.

In order to make measurements comparable, the same time intervals to all samples (Pt-Ir, Ir and gold alloy) and same storage conditions are applied for transfer cycles.

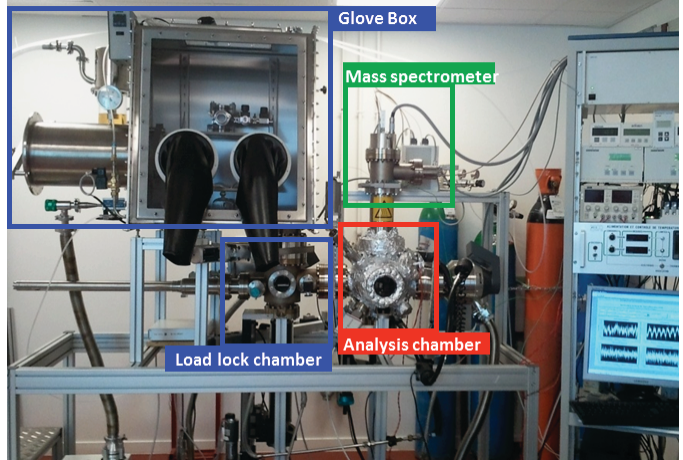

Figure 4 - Photograph of the Thermal Desorption mass Spectrometry (TDS).

Before this study, artefacts has been stored in clean room $\left(20{ }^{\circ} \mathrm{C}, 50 \%\right.$ humidity) for almost 1 year.

Figure 5 presents selected desorption curves (total pressure versus surface temperature) of the thermal desorption of Pt-Ir after a vacuum-air-vacuum, a vacuum$\mathrm{N}_{2}$-vacuum. In a first approach, cycling in air induce more desorption than a cycling in nitrogen especially from temperature of $150{ }^{\circ} \mathrm{C}$. Between $300{ }^{\circ} \mathrm{C}$ to $340{ }^{\circ} \mathrm{C}$, we can note a desorption peak that only appears for a cycling in air.

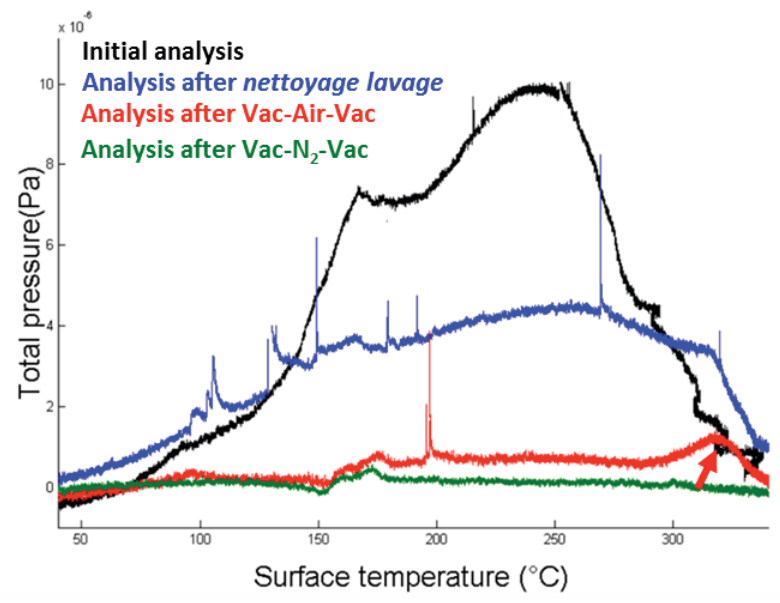

Figure 5 -Selected desorption curves after a TDS analysis.

In order to have a good comparison between each cycling, the area under desorption curve is computed. This is proportional to the desorbed amount of a given molecule or for all molecules detected by the mass spectrometer or by the variation of the pressure gauge. Figure 6 presents the global desorption rate for each cycling. As observed in desorption curves, the amount of desorbing molecules increases with the number of cycling independently of the venting process. 


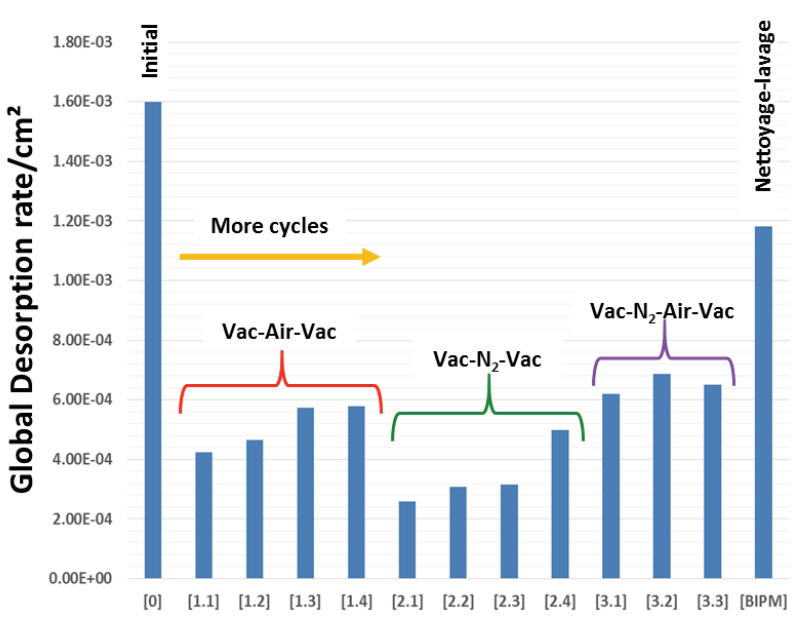

Figure 6 - Global desorption rate for each cycling transfer.

Venting cycling's on Pt-It artefact in Figures 6 to 8 show the efficiency of $\mathrm{N}_{2}$ incorporation in cycling process without air by a general decrease of the contamination. Thus the effect of Vac- $\mathrm{N}_{2}$-Var cycling on Au alloy and Ir (not presented here) is in agreement with latter results on Pt-Ir and others results in the project [24].

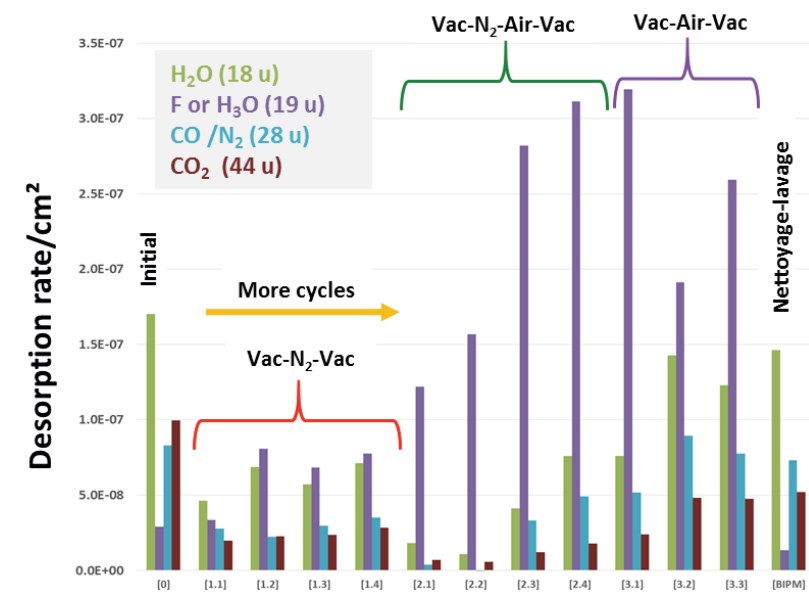

Figure 7 - Desorption rate for each cycling transfer for the main desorbing molecules.

In details and in particular for the main desorbing molecules (Figures 7 and 8), we can note that exposure to air or steam increases water contamination. In other side, nitrogen leads to increase oxygen contamination. Finally, a contamination comparison between nettoyage-lavage process and uncleaned artefact has the same level of contamination of hydrocarbon $(\mathrm{H}-\mathrm{C} / \mathrm{O})$.

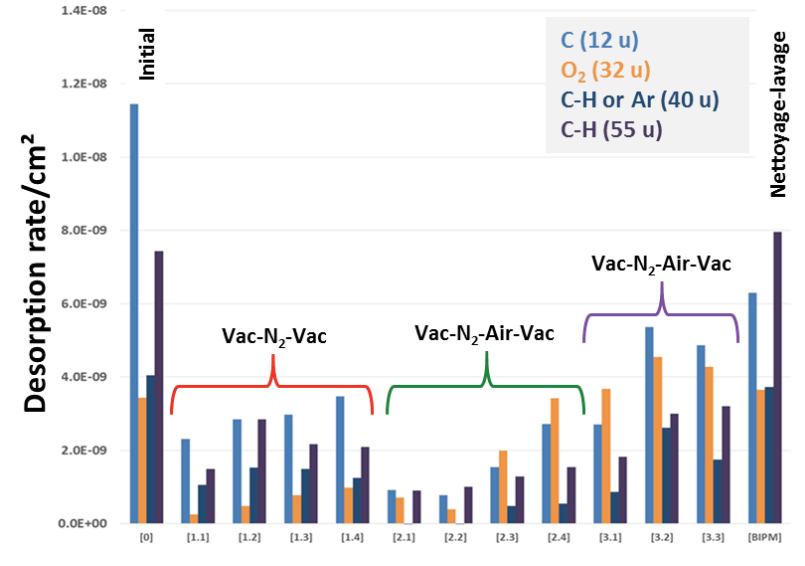

Figure 8 - Desorption rate for each cycling transfer for others desorbing molecules.

A final ranking can be established for the three different venting cycling's for Pt-Ir, Ir and gold alloy. Storage in inert gas is recommended whereas both storage in nitrogen and air not present advantage in terms of mass stability.

\section{Conclusion}

This paper has described a part of the work performed in the last three years to ensure the dissemination of the kilogram with the best uncertainties following the redefinition. A large choice of new materials has been tested for the next generation of mass standards. Tungsten and pure iridium are two promising material in terms of surface characteristics and compatible with transfers in air, nitrogen or vacuum. New methods of cleaning for mass standards has been tested in order to avoid numerous manipulations and to ensure repeatability and the best mass stability in short and long term in different atmosphere.

\section{Acknowledgments}

This work is part of the European Metrology Research Program (EMRP) SIB05 NewKILO project. It received funding from EMRP participating countries within EURAMEt and European Union. The authors also thank the partners of the NewKILO project.

\section{References}

[1] I. A. Robinson, "Watt and joule balances," Metrologia, vol. 51, no. 2, p. S1, Apr. 2014.

[2] S. Schlamminger, D. Haddad, F. Seifert, L. S. Chao, D. B. Newell, R. Liu, R. L. Steiner, and J. R. Pratt, "Determination of the Planck constant using a watt balance with a superconducting magnet system at the National Institute of Standards and Technology," Metrologia, vol. 51, no. 2, p. S15, Apr. 2014. 
[3] C. A. Sanchez, B. M. Wood, R. G. Green, J. O. Liard, and D. Inglis, "A determination of Planck's constant using the NRC watt balance," Metrologia, vol. 51, no. 2, p. S5, Apr. 2014.

[4] M. Thomas, P. Espel, D. Ziane, P. Pinot, P. Juncar, F. P. D. Santos, S. Merlet, F. Piquemal, and G. Genevès, "First determination of the Planck constant using the LNE watt balance," Metrologia, vol. 52, no. 2, p. 433, Apr. 2015.

[5] M. Stock, "Watt balance experiments for the determination of the Planck constant and the redefinition of the kilogram," Metrologia, vol. 50, no. 1, pp. R1-R16, Feb. 2013.

[6] Y. Azuma, P. Barat, G. Bartl, H. Bettin, M. Borys, I. Busch, L. Cibik, G. D’Agostino, K. Fujii, H. Fujimoto, A. Hioki, M. Krumrey, U. Kuetgens, N. Kuramoto, G. Mana, E. Massa, R. Meeß, S. Mizushima, T. Narukawa, A. Nicolaus, A. Pramann, S. A. Rabb, O. Rienitz, C. Sasso, M. Stock, R. D. V. Jr, A. Waseda, S. Wundrack, and S. Zakel, "Improved measurement results for the Avogadro constant using a 28Si-enriched crystal," Metrologia, vol. 52, no. 2, p. 360, Apr. 2015.

[7] P. Becker, H. Friedrich, K. Fujii, W. Giardini, G. Mana, A. Picard, H.-J. Pohl, H. Riemann, and S. Valkiers, "The Avogadro constant determination via enriched silicon-28," Meas. Sci. Technol., vol. 20, no. 9, p. 092002, Sep. 2009.

[8] "Resolution 1 of the 25th Meeting of the CGPM 2014 On the future revision of the International System of Units, the SI (www.bipm.org/en/CGPM/db/1/1/)."

[9] "NewKILO Website (www.newkilo.eu)."

[10] S. Davidson, J. Berry, Z. Silvestri, R. Hogstrom, and R. Green, "Addressing the requirements for the practical implementation and ongoing maintenance of the redefined kilogram," in Joint IMEKO International TC3, TC5 and TC22 Conference 2014, 2014.

[11] S. Davidson, "A review of surface contamination and the stability of standard masses," Metrologia, vol. 40, no. 6, p. 324, Dec. 2003.

[12] Z. Silvestri, R. S. Davis, G. Genevès, A. Gosset, T. Madec, P. Pinot, and P. Richard, "Volume magnetic susceptibility of gold-platinum alloys: possible materials to make mass standards for the watt balance experiment," Metrologia, vol. 40, no. 4, p. $172,2003$.

[13] P.-A. Meury and R. Molins, "Definition of a new metallic alloy for the realisation of secondary reference mass standards," MAPAN-J. Metrol. Soc. India, vol. 23, no. 3, pp. 165-172, 2008.

[14] C. Zerrouki, F. Miserey, and P. Pinot, "Répartition angulaire de la lumière diffusée par un échantillon poli du super-alliage CoCrWNi (Alacrite XSH); appplication à la détermination des paramètres statistiques caractérisant la rugosité superficielle," Eur Phys AP, vol. 1, pp. 253-259, 1998.

[15] S. Azouigui, Z. Silvestri, C. Zerrouki, S. Bouhtiyya, M. D. Plimmer, D. Spaltmann, A. Kovalev, M. Woydt, and P. Pinot, "Angle resolved scattering as a tribological investigation tool for surface characterization," Wear, vol. 326-327, pp. 58-67, Mar. 2015.

[16] G. Girard, "International report: the third periodic verification of national prototypes of the kilogram (1988-1992)," Metrologia, vol. 31, no. 4, pp. 317336, 1994.

[17] G. Girard, The washing and cleaning of kilogram prototypes at the BIPM. 1990.

[18] J. Berry, S. Davidson, P. Barat, and R. Davis, "Comparison of UV/ozone cleaning of platinum/iridium kilogram mass standards with nettoyage-lavage cleaning," Metrologia, vol. 48, no. 3, pp. 181-186, Jun. 2011.

[19] P. Fuchs, K. Marti, G. Grgić, and S. Russi, "UV/ozone cleaning of mass standards: results on the correlation between mass and surface chemical state," Metrologia, vol. 51, no. 5, pp. 387-393, Oct. 2014.

[20] P. Fuchs, K. Marti, and S. Russi, "Removal of mercury contamination on primary mass standards by hydrogen plasma and thermal desorption," Metrologia, vol. 50, no. 1, pp. 73-82, Feb. 2013.

[21] P. Fuchs, K. Marti, and S. Russi, "Materials for mass standards: long-term stability of PtIr and $\mathrm{Au}$ after hydrogen and oxygen low-pressure plasma cleaning," Metrologia, vol. 49, no. 6, pp. 615-627, Dec. 2012.

[22] K. Marti, P. Fuchs, and S. Russi, "Cleaning of mass standards: II. A comparison of new techniques applied to actual and potential new materials for mass standards," Metrologia, vol. 50, no. 1, pp. 8392, Feb. 2013.

[23] Z. Silvestri, S. Azouigui, S. Bouhtiyya, S. Macé, M. D. Plimmer, P. Pinot, F. Tayeb-Chandoul, and R. Hannachi, "Thermal desorption mass spectrometer for mass metrology," Rev. Sci. Instrum., vol. 85, no. 4, p. 045111, Apr. 2014.

[24] K. Marti, P. Fuchs, and S. Russi, "Traceability of mass II: a study of procedures and materials," Metrologia, vol. 52, no. 1, pp. 89-103, Feb. 2015. 